\title{
Investigation of clinicopathological parameters in emergency colorectal cancer surgery: a study of 67 patients
}

\author{
Amir Talebreza ${ }^{1}$, Emad Yahaghi², Ehsan Bolvardi ${ }^{3}$ Babak Masoumi ${ }^{4}$, Mehran Bahramian ${ }^{5}$, \\ Ebrahim Khodaverdi Darian ${ }^{6}$, Koorosh Ahmadi
}

1Department of Surgery, AJA University of Medical Sciences, Tehran, Iran
${ }^{2}$ Department of Molecular Biology, Baqiyatallah University of Medical Sciences,
Tehran, Iran
${ }^{3}$ Department of Emergency Medicine, Imam Reza Hospital, Mashhad University
of Medical Sciences, Mashhad, Iran
${ }^{4}$ Department of Emergency Medicine, Isfahan University of Medical Sciences, Isfahan,
Iran
${ }^{5}$ Department of Emergency Medicine, Madani Hospital, Alborz University of Medical
Sciences, Karaj, Iran
${ }^{6}$ Young Researchers and Elite Club, North Tehran Branch, Islamic Azad University,
Tehran, Iran
${ }^{7}$ Department of Emergency Medicine, Alborz University of Medical Sciences, Karaj, Iran

Submitted: 25 May 2016

Accepted: 26 June 2016

Arch Med Sci 2017; 13, 6: 1394-1398

DOI: 10.5114 /aoms.2016.61385

Copyright $\odot 2016$ Termedia \& Banach

\section{Abstract}

Introduction: The aim of the present study was to establish, having adjusted for case mix, the size of the differences in postoperative mortality and 5 -year survival between patients presenting as an emergency with evidence of obstruction and perforation and the association of clinicopathological factors with mortality (bivariate analyses).

Material and methods: The study included 67 patients who presented with colorectal cancer (CRC) between 2009 and 2013 in Iran. The mean age of the patients was 59.7 years. Of the 67 patients, 37 (55.22\%) were male and $30(44.77 \%)$ were female. Certain parameters that correlated with CRC and surgical treatment were investigated

Results: Our results showed that $46(68.65 \%)$ patients had obstruction, while perforation was observed in 21 (31.34\%) cases. Among the patients with obstruction, obstruction of the right colon was observed in 29 (43.28\%) cases. There was no significant difference in mortality rate between right and left colonic obstruction. Based on the bivariate analyses, our findings showed that death of patients was significantly related to tumor grade ( $p=$ 0.02 ) and TNM staging $(p=0.026)$, but no association was found between other parameters and death, including age, sex, and tumor site.

Conclusions: Compared with patients who undergo elective surgery for colon cancer, those who present as an emergency with evidence of obstruction or perforation have higher postoperative mortality rates and poorer cancer-specific survival. Also, colorectal cancer patients with emergency surgery showed aggressive histopathology and an advanced stage.

Key words: colorectal cancers, emergency, surgery, histopathological factors, survival.

\author{
Corresponding author: \\ Koorosh Ahmadi \\ Department \\ of Emergency Medicine \\ Alborz University \\ of Medical Sciences \\ Karaj, Iran \\ Phone: 00989124806577 \\ E-mail: kooroshem@gmail.com
}




\section{Introduction}

Colorectal cancer (CRC) is known as one of the commonest cancers worldwide, with 850,000 new cases and 500,000 deaths annually [1, 2]. Elective surgical resection is the first option of cancer treatment, but many colorectal cancer cases present as an emergency [1-7].

Moreover, it has been estimated that $6 \%$ to $30 \%$ of patients have symptoms or late complications associated with the disease. It has been reported that most patients have an advanced stage at the time of diagnosis and are referred for surgery with curative intent. Previous investigations have reported that a high rate of mortality and shorter survival may be related to emergency treatment [8-10]. Emergency procedures have been shown to have worse outcomes when compared with elective resections in patients suffering from colorectal cancer. The prognosis is poorer when patients present for emergency compared to elective treatment. High rates of morbidity and mortality are associated with colorectal cancer in complicated forms including intestinal necrosis, obstruction, perforation, localized peritonitis, diffuse and aggravated by others diseases [11-13].

The aim of this study was to evaluate the significance of clinicopathological characteristics of colorectal cancer patients presenting as an emergency.

\section{Material and methods}

Sixty-seven patients who underwent resection for colorectal cancer between 2009 and 2013 in the Emergency Room Service of Tehran hospitals were included in the study. The tissues were confirmed by pathological evaluation. The mean age of the patients was 59.7 years. Of the 67 patients, 37 (55.22\%) were male and 30 (44.77\%) were female. Signs and symptoms of patients are summarized in Table I.

The following parameters correlated with CRC: complications of the cancer in the clinical presentation including obstruction or perforation, site of tumor in the large intestine. Clinical features, length of stay, outcomes, and pathological results were obtained in this study. The tumor stage and grade were also determined in this study. The clinicopathological factors of the patients are shown in Table II.

\section{Statistical analysis}

SPSS software version 16.0 for Windows (SPSS Inc, IL, USA) was used to evaluate all the data. The $\chi^{2}$ test was used to evaluate the association of variables. Differences were considered statistically significant when $p$ was less than 0.05 . The bivariate analysis was used to compare parameters including age, sex, tumor site, staging and tumor grade with death.

\section{Results}

The surgical treatment was as follows: tumor resection with primary anastomosis (44.77\%); $38.80 \%$ of patients were treated with colostomy. The signs and symptoms of patients with CRC are summarized in Table I. Bleeding was never seen among the patients. The tumor location, tumor grade and tumor staging are shown in Table II. In addition, 9 (13.43\%) cases had distant metastases, most of them in the liver.

The average time of hospitalization in the intensive care unit (ICU) was 10.3 days and perioperative mortality was $22.38 \%$ (15 patients, 1 month after surgery). Our results showed that $46(68.65 \%)$ cases had obstruction, while perforation was observed in 21 (31.34\%) cases. Among the patients with obstruction, obstruction of the right colon was observed in 29 (43.28\%) cases. Our findings showed that mortality rate was not associated with tumor site and right or left colonic obstruction.

Based on the bivariate analyses, our results showed that death of patients was significantly related to tumor grade $(p=0.02)$ and TNM staging $(p=0.026)$, but no association was found between other parameters and death, including age, sex, and tumor site (Table II).

\section{Discussion}

It has been reported that a high proportion of colorectal cancer cases may be treated as an emergency [1-7]. Emergency presentation has been shown to have worse outcomes when compared with elective resections in patients with colorectal cancer. High rates of morbidity and mortality are associated with colorectal cancer in complicated forms including intestinal necrosis, obstruction, perforation, localized peritonitis or diffuse and aggravated by other diseases [14-16].

Operative mortality due to obstruction or CRC perforation was estimated to be from $16 \%$ to $38 \%$ [17]. In our study, the average time of hospitalization in the ICU was 10.3 days and perioperative

Table I. Signs and symptoms of patients

\begin{tabular}{|lcc|}
\hline Signs and symptoms & $\begin{array}{c}\text { Number of } \\
\text { patients }\end{array}$ & Percent \\
\hline Abdominal pain & 65 & 97.01 \\
\hline Anorexia & 55 & 82.08 \\
\hline Vomiting & 38 & 56.71 \\
\hline Tenesmus & 10 & 14.92 \\
\hline Loss of weight & 40 & 59.70 \\
\hline
\end{tabular}


Table II. Association of clinicopathological factors with death (bivariate analyses)

\begin{tabular}{|c|c|c|c|c|}
\hline Parameters & $\%$, number & Death (\%) & Risk ratio & $P$-value \\
\hline \multicolumn{5}{|l|}{ Age group [years]: } \\
\hline$<64$ & $53.73 ; 36$ cases & $9(25)$ & 0.65 & 0.526 \\
\hline$>64$ & 46.26; 31 cases & $6(19.35)$ & & \\
\hline Gender: & & & & 0.623 \\
\hline Female & 44.77; 30 cases & $7(23.33)$ & 0.83 & \\
\hline Male & $55.22 ; 37$ cases & $8(21.62)$ & & \\
\hline Site of tumor: & & & & 0.724 \\
\hline Right colon & $49.23 ; 33$ cases & $7(21.21)$ & 0.91 & \\
\hline Sigmoid & $16.41 ; 11$ cases & $1(9.09)$ & 0.42 & \\
\hline Transverse colon & $11.94 ; 8$ cases & $2(25)$ & 0.68 & \\
\hline Left colon & $19.40 ; 13$ cases & $4(26.66)$ & 0.71 & \\
\hline Upper rectum & $2.98 ; 2$ cases & $1(30.76)$ & 0.42 & \\
\hline TNM staging: & & & & 0.026 \\
\hline । & $5.97 ; 4$ cases & $0(0)$ & 0 & \\
\hline II & $44.77 ; 30$ cases & $2(6.66)$ & 0.55 & \\
\hline III & $31.34 ; 21$ cases & $6(28.57)$ & 2.27 & \\
\hline IV & $19.40 ; 13$ cases & $7(53.84)$ & 2.61 & \\
\hline Histological grade: & & & & 0.02 \\
\hline । & 10.44; 7 cases & $1(14.28)$ & 0.77 & \\
\hline ॥ & $58.20 ; 39$ cases & $6(15.38)$ & 2.41 & \\
\hline III & $31.34 ; 21$ cases & $8(38.09)$ & 2.68 & \\
\hline
\end{tabular}

mortality was $22.38 \%$ (15 patients, 1 month after surgery). It has been postulated that patient's poor clinical condition including dehydration, malnutrition, and advanced age may be involved in this matter.

Smothers et al. [18] reported that an emergency colectomy can be an independent negative prognostic factor in the context of morbidity and mortality in CRC patients.

A previous study showed a morbidity and mortality rate of $41 \%$ and $15 \%$ in patients operated on for obstruction or perforation respectively [19]. Ascanelli et al. [20] reported $27 \%$ morbidity and $12 \%$ mortality in patients with colorectal cancer who were referred for emergency surgery. Moreover, it was reported that overall survival and percentage of survival are lower in CRC patients who undergo an emergency operation [21].

Our results showed that obstruction was observed in 46 (68.65\%) cases and 21 (31.34\%) cases had perforation. Among the patients with obstruction, obstruction of the right colon was observed in 24 (35.82\%) cases. The majority of tumors were located in the right colon $(49.23 \%$;
33 cases), and others were located in other parts (Table II). Our findings showed that mortality rate was not associated with tumor site and right or left colonic obstruction. It has been previously reported that lesions are most common on the right side in elderly patients presenting acutely [22].

It has been reported that the incidence of right colon obstruction may range between 15\% and $44 \%$ worldwide. High numbers of patients are needed to interpret this matter. In a series by Smithers et al. [23], emergency procedures of right hemicolectomies for colon carcinoma were reported. On the other hand, a previous study did not find any significant differences in the mortality rate between right-sided and left-sided lesions in CRC patients [24]. However, it has been suggested that patients with one-stage surgery will have shorter survival than patients with non-obstructing lesions [25].

In the present study, 9 (13.43\%) cases had distant metastases, most of which were in the liver. It has been previously reported that up to $30 \%$ of patients undergoing a curative operation had hepatic metastases at the time of presentation, and the presence of such occult metastases can be 
associated with death from disseminated disease within 5 years [26].

In the present study, our findings showed that death of patients was significantly related to tumor grade $(p=0.02)$ and TNM staging $(p=0.026)$. Based on the bivariate analyses, no association was found between other parameters and death, including age, gender, and tumor site. These clinicopathological parameters were previously reported by different authors for various cancers [27-34]. It has been reported that advanced CRC is related to higher incidence of complications and mortality [35]. The limitation of this study is the number of patients, and a larger sample size is needed to evaluate the significance of clinicopathological characteristics in patients with colorectal cancer.

In conclusion, our results indicated that patients with emergency surgery showed aggressive histopathology and an advanced stage.

\section{Conflict of interest}

The authors declare no conflict of interest.

\section{References}

1. Tan E, Tilney H, Thompson M, Smith J, Tekkis PP. Association of coloproctology of Great Britain and Ireland. The United Kingdom national bowel cancer project - epidemiology and surgical risk in the elderly. Eur J Cancer 2007; 43: 2285-94.

2. Ries LAG, Eisner MP. SEER Cancer Statistics Review, 1973-1997. Bethesda, MD: National Cancer Institute 2000.

3. Zavoral M, Suchanek S, Zavada F, et al. Colorectal cancer screening in Europe. World J Gastroenterol 2009; 15: 5907-15.

4. Basdanis G, Papadopoulos VN, Michalopoulos A, et al. Colorectal cancer in patients over 70 year of age: determinants of outcome. Tech Coloproctol 2004; 8: 112-5.

5. Gingras D, Béliveau R. Colorectal cancer prevention through dietary and lifestyle modifications. Cancer Microenviron 2011; 4: 133-9.

6. Phang PT, MacFarlane JK, Taylor RH, Chiefetz R, Davis N, Hay J. Effect of emergent presentation on outcome from rectal cancer management. Am J Surg 2003; 185: 450-4.

7. Ponz de Leon M, Sassatelli R, Scalmati A, Di Gregorio C, Fante R, Zanguieri G. Descriptive epidemiology of colorectal câncer in Italy: the 6 year experience of a specialized registry. Eur J Cancer 1993; 29: 367-71.

8. Anderson JH, Hole D, McArdle CS. Elective versus emergency surgery for patients with colorectal cancer. $\mathrm{Br}$ J Surg 1992; 79: 706-9.

9. McArdle CS, Anderson JH. Obstructing large bowel cancer. In: Colorectal cancer. McArdle CS, Kerr DJ, Boyle P (eds.). Isis Medical Media, Oxford 2000; 195-207.

10. Carraro PG, Segala M, Cesana BM, Tiberio G. Obstructing colonic cancer: failure and survival patterns over a ten-year follow-up after one-stage curative surgery. Dis Colon Rectum 2001; 44: 243-50.

11. Tekkis PP, Kinsman R, Thompson MR, Statamakis JD. The association of coloproctology of Great Britain and Ireland study of large bowel obstruction caused by colorectal cancer. Ann Surg 2004; 240: 76-81.
12. Letiman IM, Sullivan JD, Brams D, De Cosse JJ. Multivariate analysis of morbity and mortality from the initial surgical management of obstructing carcinoma of the colon. Surg Gynecol Obstet 1992; 174: 513-8.

13. Runkel NS, Hinz U, Lehnert T, Buhr HJ, Herfarth C. Improved outcome after emergency surgery for cancer of the large intestine. Br J Surg 1998; 85: 1260-5.

14. Chen HS, Sheen-Chen SM. Obstruction and perforation in colorectal adenocarcinoma: an analysis of prognosis and current trends. Surgery 2000; 127: 370-6.

15. Bosman FT, Carneiro F, Hruban RH, Theise ND. WHO classification of tumours. Vol. 3. IARC WHO Classification of Tumours, No. 3; Washington 2010.

16. Edge SB, Byrd DR, Compton CC, Fritz AG, Greene FL, Trotti $A$ (eds.). AJCC cancer staging manual. Springer, London 2010.

17. Crucitti F, Sofo L, Doglietto GB, Bellantone R, Ratto C, Bossola M. Prognostic factors in colorectal cancer: current status and new trends. J Surg Oncol 1991; 48: 76-82.

18. Smothers L, Hynan L, Fleming J, Turnage R, Simmang C, Anthony T. Emergency surgery for colon carcinoma. Dis Colon Rectum 2003; 46: 24-30.

19. Tobaruela E, Camuñas J, Navascúes JM, Díez M, Ratia T, Martin A. Medical factors in the morbidity and mortality associated with emergency colorectal cancer surgery. Rev Esp Enferm Dig 1997; 89: 13-22.

20. Ascanelli A, Navarra G, Tonini G, Feo C, Zerbinati A, Pozza E. Early and late outcome after surgery for colorectal cancer: elective versus emergency surgery. Tumori 2003; 89: 36-41.

21. McArdle CS, Mc Millan D, Hole DJ. The impact of blood loss, obstruction and perforation on survival in patients undergoing curative resection for colon cancer. $\mathrm{Br}$ I Surg 2006; 93: 383-8.

22. Waldron RP, Donovan IA, Drumm J, Mottram SN, Tedman S. Emergency presentation and mortality from colorectal cancer in the elderly. Br J Surg 1986; 73: 214-6.

23. Smithers BM, Theile DE, Cohen JR, Evans EB, Davis NC. Emergency right hemicolectomy in colon carcinoma: a prospective study. Aust N Z J Surg 1986; 56: 749-52.

24. Lee Y, Law W, Chu K, Poon R. Emergency surgery for obstructing colorectal cancers: a comparison between right sided and left sided lesions. J Am Coll Surg 2001; 192: 719-25.

25. Setti Carraro P, Segala M, Cesana B, Tiberio G. Obstructing colonic cancer: failure and survival over a ten-year follow-up after one-stage curative surgery. Dis Colon Rectum 2001; 44: 243-50.

26. Finlay IG, Meek D, Brunton F, McArdle CS. Growth rate of hepatic metastases in colorectal cancer. Br I Surg 1988; 75: 641-4.

27. Ajdarkosh H, Dadpay M, Yahaghi E, Pirzaman ER, Darian EK, Mokarizadeh A. Decrease expression and clinicopathological significance of miR-148a with poor survival in hepatocellular carcinoma tissues. Diagn Pathol 2015; 10: 135.

28. Treska V, Skalicky T, Sutnar A, et al. Prognostic importance of some clinical and therapeutic factors for the effect of portal vein embolization in patients with primarily inoperable colorectal liver metastases. Arch Med Sci 2013; 9: 47-54.

29. Mirghasemi A, Taheriazam A, Karbasy SH, Shakeri M, Yahaghi E, Mokarizadeh A. Down-regulation of miR-133a and miR-539 are associated with unfavorable prognosis in patients suffering from osteosarcoma. Cancer Cell Int 2015; 15: 86

30. Tavasoly A, Gholami H, Rostami A, Touni SR, Khaleghian P, Mokarizadeh A. Clinico-histopathologic and outcome 
features of cutaneous infundibular keratinizing acanthoma: a case report and literature review. World I Surg Oncol 2014; 12: 173.

31. Janež J, Korać T, Kodre AR, Jelenc F, Ihan A. Laparoscopically assisted colorectal surgery provides better shortterm clinical and inflammatory outcomes compared to open colorectal surgery. Arch Med Sci 2015; 11: 1217-26.

32. Manesh JY, Shafiee R, Pedram B, Javanbakht J, Mokarizadeh A, Khadivar F. Improving the diagnosis, treatment, and biology patterns of feline mammary intraepithelial lesions: a potential model for human breast masses with evidence from epidemiologic and cytohistopathologic studies. Tumour Biol 2014; 35: 12109-17.

33. Smolińska K, Paluszkiewicz P. Risk of colorectal cancer in relation to frequency and total amount of red meat consumption. Arch Med Sci 2010; 6: 605-10.

34. Maghsoudi O, Mirjalili SH, Dolatabadi M, Joshaghani MF, Yahaghi E, Mokarizadeh A. Investigations of renal function using the level of neutrophil gelatinase-associated lipocalin associated with single-dose of cisplatin during chemotherapy. Diagn Pathol 2015; 10: 98.

35. Biondo S, Parés D, Frago R, Martí-Ragué J, Kreisler E, De Oca J. Large bowel obstruction: predictive factors for postoperative mortality. Dis Colon Rectum 2004; 47: 1889-97. 